\title{
TREATMENT OF RESIDUE FROM THE MOHR METHOD WITH IMMOBILIZATION IN PVC CAPSULE/ BODY-OF-PROOF
}

\author{
SILVA, Juliana Monteiro1*; THEOPHILO, Paulo Henrique Medeiros; \\ BORGES, Simone da Silveira Sá3; \\ 1,2,3 Universidade Federal do Ceará, Centro de Ciências, Departamento de Química Analítica e Físico-Química, \\ Bloco 940, Caixa Postal 6021, CEP 60455-970, Campus do Pici Prisco Bezerra, Fortaleza - CE, Brasil. \\ (fone: +55 853366 9045) \\ * Autor correspondente \\ e-mail: juliana_monteiro_jk@hotmail.com \\ Received 4 July 2015; received in revised form 6 July 2015; accepted 24 August 2015
}

\section{RESUMO}

O desenvolvimento econômico atual leva a uma grande produção de resíduos, e estes estão inseridos nas atividades cotidianas da universidade. O correto gerenciamento desses resíduos é essencial para minimizar os riscos ao meio ambiente, bem como à comunidade acadêmica. Atualmente o maior desafio é com os resíduos laboratoriais, pois são de uma enorme complexidade e diversidade. Assim, este trabalho tem como objetivo propor o gerenciamento ambientalmente adequado do resíduo oriundo do Método de Mohr gerado nos Laboratório de Ensino de Química Analítica, que contém cromo hexavalente, metal pesado altamente tóxico e danoso ao meio ambiente. No estudo foram utilizados dois agentes redutores de cromo hexavalente à cromo trivalente, bissulfito de sódio e tiossulfato de sódio, possibilitando, após o tratamento, o descarte do sobrenadante em ambos os casos, visto que as concentrações de cromo total foram reduzidas em 99,67\% (média), próximas às estabelecidas pela legislação. Para a disposição final do sólido oriundo dos tratamentos foi feita a imobilização em cápsulas de Policloreto de Vinila/Corpo de Prova, que se mostrou uma solução limpa, rápida e simples podendo ser aplicada a muitos outros resíduos sólidos contendo metais pesados.

Palavras-chave: Resíduo laboratorial. Cromo. Minimização.

\begin{abstract}
The actual economic development leads to a big waste production, and these are inserted into the daily activities of the University. The correct management of these wastes is essential to minimize the risks to the environment, as well as the academic community. Currently the greatest challenge is with the laboratory waste, because they are of enormous complexity and diversity. Thus, this work proposes environmentally ap propriate management of the waste comes from the Mohr Method generated in the Teaching Laboratory of Analytical Chemistry, which contains hexavalent chromium, a heavy metal highly toxic and nocuous to the environment. In the study was used two reducing agents of hexavalent chromium to the trivalent chromium, sodium bisulfite and sodium thiosulfate, allowing, after treatment, discard the supernatant in both cases, since the total concentrations of chromium were reduced by $99.67 \%$ (average), next to those laid down by the law. The final disposition of the solid coming from the treatments was made by immobilization in capsules of polyvinyl chloride/Body-of-proof, which proved to be a clean, fast and simple solution that can be applied to many other solid wastes which contains heavy metal.
\end{abstract}

Keywords: Laboratory waste. Chrome. Minimization. 


\section{INTRODUÇÃO}

O desenvolvimento econômico atual apresenta caráter predatório, impactante ao meio ambiente, que leva à produção de resíduos, e estes estão inseridos nas atividades cotidianas da universidade, como ensino, pesquisa e extensão. $O$ correto gerenciamento desses resíduos é essencial para minimizar os riscos ao meio ambiente, bem como à comunidade acadêmica. Como as universidades são instituições responsáveis pela formação de seus estudantes $e$, consequentemente, influenciam em seu comportamento como cidadãos, estas devem estar conscientes do problema de geração, armazenamento, tratamento e destinação final de seus resíduos. Em 1990, as universidades começaram a discutir 0 gerenciamento de resíduos laboratoriais e desde então vem realizando trabalhos que tem como objetivos gerenciar e tratar seus materiais residuais de forma a diminuir o impacto causado ao meio ambiente (Gioli-lima e Lima, 2003).

Dessa forma, foi criado em 2005 na Universidade Federal do Ceará (UFC) o Programa Gerenciamento de Resíduos (PROGERE), que reúne um conjunto de procedimentos e ações visando a implantação de um sistema integrado de coleta seletiva, redução, reutilização, reciclagem e destinação final dos diversos tipos de resíduos gerados nas atividades de ensino, pesquisa, extensão e administração da UFC.

O PROGERE foi estruturado em três plataformas de acordo com o desenvolvimento das ações específicas: gerenciamento de resíduos recicláveis, gerenciamento de resíduos laboratoriais e educação socioambiental. O gerenciamento de resíduos laboratoriais é o maior desafio para o programa, pois estes são de uma enorme diversidade e complexidade. Assim, o programa tem buscado criar metodologias de tratamento para os principais resíduos gerados nos laboratórios de ensino da UFC.

Neste trabalho será abordado o tratamento do resíduo oriundo do método de Mohr, que é utilizado nas disciplinas experimentais de Química Analítica para os cursos dos diversos Centros e Faculdades da UFC. O método de Mohr é um método analítico clássico argentimétrico de volumetria de precipitação direta, aplicado para quantificar íons cloreto, brometo e iodeto em uma amostra, sendo mais comumente aplicado ao íon cloreto.

Este método tem grande importância, pois a determinação do íon cloreto é utilizada no controle de qualidade em diversos setores como, por exemplo, no controle de qualidade da água, na indústria farmacêutica, na indústria de alimentos, no controle de estações de tratamento de esgoto, entre outros. O resíduo oriundo deste método é formado por um sobrenadante, objeto deste trabalho, contendo, principalmente, o íon cromato $\left(\mathrm{CrO}_{4}{ }^{2-}\right)$ e um precipitado constituído em sua maioria por cloreto de prata $(\mathrm{AgCl})$ e cromato de prata $\left(\mathrm{Ag}_{2} \mathrm{CrO}_{4}\right)$.

O cromo é considerado um metal essencial, pois faz parte do metabolismo energético, atuando na forma de $\mathrm{Cr}$ (III) como cofator para a ação da insulina na formação de um complexo terciário com o receptor da mesma (Vaz e Lima, 2003 apud Goyer, 1991). Entretanto, o $\mathrm{Cr}(\mathrm{VI})$ na forma de íon cromato em pesquisa realizada utilizando animais em condições aproximadas às condições de trabalho, a substância mostrou-se cancerígena e a mutação genética foi comprovada em experiência com mamíferos, concluindo-se que a exposição de seres humanos a esta substância pode acarretar lesões transmissíveis aos descendentes (Labmaster, 2011).

De acordo com Gutterres (2011) o Cr(VI) penetra com facilidade por meio da membrana celular, e é convertido em $\mathrm{Cr}$ (III). Por sua vez, o $\mathrm{Cr}$ (III) é solúvel somente em baixos valores de $\mathrm{pH}$, e estes são geralmente menores do que aqueles normalmente encontrados em sistemas biológicos, ou quando complexado com moléculas orgânicas de baixo peso molecular, que possuem pouca mobilidade através da membrana celular. A conversão do $\mathrm{Cr}(\mathrm{VI})$ à $\mathrm{Cr}$ (III) no organismo pode acarretar em danos à estrutura celular e também causar um desequilíbrio devido ao aumento da concentração de $\mathrm{Cr}(\mathrm{III})$, que passa a ser tóxico em níveis mais elevados (Paulinho, 1993). O cromo também se apresenta tóxico a vida aquática, dependendo das espécies, tempo de exposição e fatores ambientais como temperatura, $\mathrm{pH}$, oxigênio dissolvido e dureza.

Há cinco anos o resíduo oriundo do 
método de Mohr produzido no Departamento de Química Analítica e Físico-química (DQAFQ) da UFC não tinha destino adequado. A partir de então foi implementada a coleta desse material residual no DQAFQ, sendo armazenado para futuro tratamento e descarte ambientalmente correto. Paralelamente a isso, foi realizado um trabalho de conscientização dos corpos discente, docente e técnicos de laboratório que estariam envolvidos na geração desse resíduo.

Com base nos dados de Cavalcante, Silva e Borges (2012), que estimou a quantidade média de resíduos gerados no Laboratório de Química Analítica Quantitativa, são produzidos $8 \mathrm{~L}$ do resíduo proveniente do método de Mohr por semestre, originando até 2014.2 116L de resíduo estocado.

Assim, o objetivo deste trabalho é propor o gerenciamento do resíduo do método de Mohr gerado nas aulas de Volumetria de Precipitação nos Laboratório de Química Analítica Quantitativa do $D A Q F Q$, realizando o tratamento e disposição final ambientalmente correta.

\section{MATERIAIS E MÉTODOS}

\section{Tratamento preliminar do resíduo}

O material residual do método de Mohr é constituído de uma parte sólida (precipitado) e uma parte líquida (sobrenadante). $\mathrm{Na}$ parte sólida há dois precipitados, o $\mathrm{AgCl}$ e $\circ \mathrm{Ag}_{2} \mathrm{CrO}_{4}$ contaminados com $\mathrm{CaCO}_{3}$, e no sobrenadante há a presença do metal cromo com número de oxidação +6 na forma de íon cromato.

Inicialmente o sobrenadante é separado do precipitado por decantação e em seguida com o auxilio de um papel de filtro qualitativo o resíduo é filtrado. Então, o precipitado é levado para secar na estufa e depois armazenado para futuro tratamento. E o sobrenadante, contendo $\mathrm{Cr}(\mathrm{VI})$ é pré-concentrado em chapa aquecedora para o tratamentos descritos a seguir.

\section{Tratamento do resíduo}

sobrenadante contendo $\mathrm{Cr}(\mathrm{VI})$ foi
tratado seguindo os procedimentos de precipitação apresentados na literatura (Armour, 2005). Estes processos consistem em converter o $\mathrm{Cr}(\mathrm{VI})$ em $\mathrm{Cr}(\mathrm{III})$ por meio de uma reação de oxirredução, a qual utiliza reagentes redutores como o bissulfito de sódio $\left(\mathrm{NaHSO}_{3}\right)$ e tiossulfato de sódio $\left(\mathrm{Na}_{2} \mathrm{~S}_{2} \mathrm{O}_{3}\right)$. Em seguida realiza-se a precipitação do $\mathrm{Cr}(\mathrm{III})$, como hidróxido de cromo (III), por meio da adição do reagente hidróxido de sódio $(\mathrm{NaOH})$.

\section{Tratamento com bissulfito de sódio}

Dispondo o sobrenadante filtrado em um béquer, adiciona-se $\mathrm{NaHSO}_{3}$, sob agitação, até que ocorra a mudança na coloração, do amarelo para verde permanente. Essa mudança de coloração está relacionada a redução do $\mathrm{Cr}(\mathrm{VI})$, que é o estado de oxidação do cromo no cromato, para $\mathrm{Cr}(\mathrm{III})$. Acrescenta-se um pequeno excesso do reagente para que seja garantida a eficácia da reação, pois o bissulfito em pH neutro tende a formar íon sulfito segundo a reação representada na Equação 1.

$\mathrm{HSO}_{3(\mathrm{aq})}^{-{ }^{-}} \leftrightarrow \mathrm{SO}_{3}{ }^{2-}{ }_{(\mathrm{aq})}+\mathrm{H}^{+}{ }_{(\mathrm{aq})}$

Logo em seguida adicionou-se gotas de $\mathrm{NaOH} 6$ mol.L-1 ${ }^{-1}$ sob agitação, até $\mathrm{pH} \geq 10$ para a formação do $\mathrm{Cr}(\mathrm{OH})_{3}$ que é muito pouco solúvel em água; estas duas etapas podem ser representadas pela Equação 2 e 3.

$$
\begin{aligned}
& 2 \mathrm{CrO}_{4}^{2-}{ }_{(\mathrm{aq})}+3 \mathrm{HSO}_{3(\mathrm{aq})}^{-}+5 \mathrm{H}_{2} \mathrm{O}_{(\mathrm{l})} \rightarrow 2 \mathrm{Cr}^{3+}{ }_{(\mathrm{aq})}+3 \\
& \mathrm{HSO}_{4(\mathrm{aq})}^{-}+10 \mathrm{OH}_{(\mathrm{aq})}^{-}
\end{aligned}
$$

$$
\mathrm{Cr}_{(\mathrm{aq})}^{3+}+3 \mathrm{OH}_{(\mathrm{aq})}^{-} \rightarrow \mathrm{Cr}(\mathrm{OH})_{3(\mathrm{~s})}
$$

O sistema é deixado em repouso até o dia seguinte, quando é feito novamente uma decantação e filtração para separar o precipitado de $\mathrm{Cr}(\mathrm{OH})_{3}$ do sobrenadante, que deve estar o mais isento possível de cromo para que, então, possa ser descartado adequadamente. $O$ precipitado de $\mathrm{Cr}(\mathrm{OH})_{3}$ é seco em estufa à $110^{\circ} \mathrm{C}$ para armazenamento correto.Para o descarte adequado do sobrenadante é necessário verificar através de análise por absorção atômica se a concentração de cromo total remanescente está de acordo com a resolução N³57/2005 
CONAMA. O sobrenadante deve ser descartado na pia sob a água corrente, se a concentração de cromo total for igual ou menor que $0,5 \mathrm{mg}^{-1}$; se estiver acima é necessário realizar o tratamento novamente até que o sobrenadante esteja apto a ser descartado.

\section{Tratamento com tiossulfato de sódio}

$\mathrm{O}$ tratamento com o $\mathrm{Na}_{2} \mathrm{~S}_{2} \mathrm{O}_{3}$ segue os mesmos procedimentos do tratamento com $\mathrm{NaHSO}_{3}$, a única diferença é que a reação de redução com tiossulfato requer que o meio seja ácido, portanto, antes de tratar com o reagente é necessário adicionar algumas gotas de solução de $\mathrm{H}_{2} \mathrm{SO}_{4} 3$ mol.L-1 ate $\mathrm{pH} \leq 3$, quando a cor amarela, característica do íon cromato, muda permanentemente para laranja, que é característico do íon dicromato, como mostra a Equação 4.

$2 \mathrm{CrO}_{4}{ }^{2-}{ }_{(\mathrm{aq})}+\mathrm{H}^{+}{ }_{(\mathrm{aq})} \rightarrow \mathrm{Cr}_{2} \mathrm{O}_{7}{ }^{2-}{ }_{(\mathrm{aq})}+\mathrm{H}_{2} \mathrm{O}_{(\mathrm{l})}$

A reações que ocorrem no tratamento são representadas pelas Equações 5 e 6 .

$\mathrm{Cr}_{2} \mathrm{O}_{7}{ }^{2-}{ }_{(\mathrm{aq})}+3 \mathrm{~S}_{2} \mathrm{O}_{3}{ }^{2-}{ }_{(\mathrm{aq})}+26 \mathrm{H}^{+}{ }_{(\mathrm{aq})} \rightarrow \mathrm{Cr}^{3+}{ }_{(\mathrm{aq})}+6$

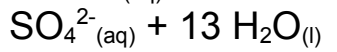

$\mathrm{Cr}^{3+}{ }_{(\mathrm{aq})}+3 \mathrm{OH}_{(\mathrm{aq})}^{-} \rightarrow \mathrm{Cr}(\mathrm{OH})_{3(\mathrm{~s})}$

Os fluxogramas (Figura 1 e Figura 2) apresentam as etapas de tratamento do sobrenadante com bissulfito de sódio e tiossulfato de sódio, respectivamente. O fluxograma (Figura 3) mostra a sequência dos procedimentos para a realização da gestão do resíduo desde a coleta até a disposição final.

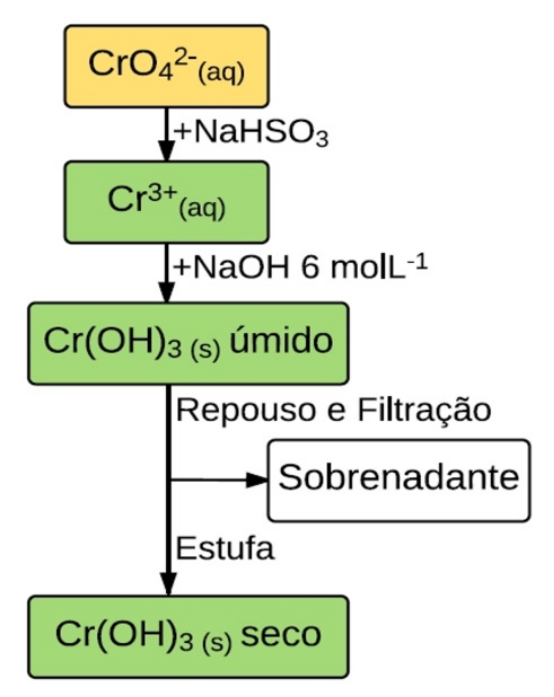

Figura 1. Fluxograma dos tratamentos do sobrenadante do resíduo oriundo do método de Mohr com bissulfito de sódio

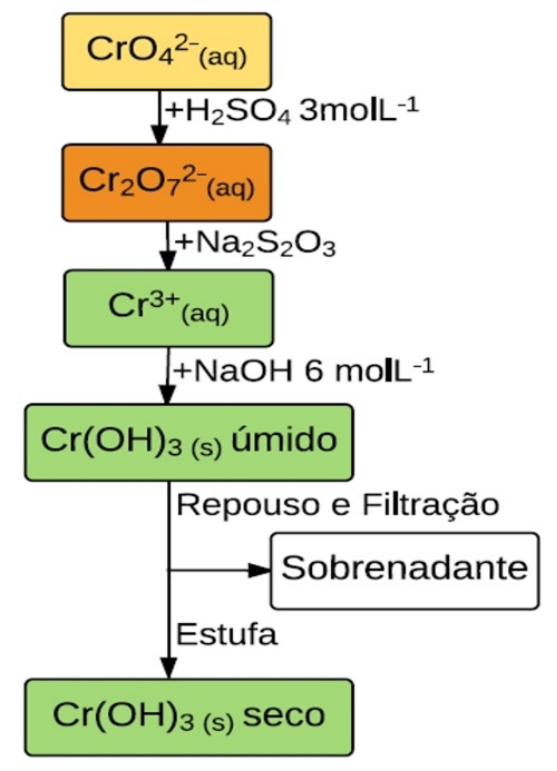

Figura 2. Fluxograma dos tratamentos do sobrenadante do resíduo oriundo do método de Mohr com tiossulfato de sódio Imobilização

O resíduo de $\mathrm{Cr}(\mathrm{OH})_{3}$ gerado no tratamento do sobrenadante foi imobilizado em cápsulas de PVC revestidos com concreto.

Assim, foi elaborada a imobilização deste resíduo, conforme o seguinte procedimento: após a filtração e secagem do precipitado, o papel de filtro contendo o sólido seco foi dobrado (Figura 4a) e depois compactado dentro de uma cápsula de PVC (cano de PVC cortado), que tem 13,2 cm 
de comprimento e $4 \mathrm{~cm}$ de diâmetro, vedado nas extremidades por tampas de PVC DN 40 NBR 5688 (Figura 4b). A cápsula foi encerrada em um corpo de prova, que tem $20 \mathrm{~cm}$ de comprimento e $10 \mathrm{~cm}$ de diâmetro (Figura 4c), utilizando o concreto produzido como resíduo nas disciplinas de Materiais de construção I e II ofertadas pelo Departamento de Engenharia Estrutural e Construção Civil (DEECC) do Centro de Tecnologia (CT) da UFC. O concreto suporta 20 Mpa, que é o mesmo utilizado na construção de alicerce de prédios. A cápsula foi localizada exatamente no meio do corpo de prova, com duas camadas de concreto acima e abaixo, para sua maior proteção. Estas cápsulas encerradas em corpos de prova (Figura 4d) são destinadas à ornamentação de jardins na UFC.

O corpo de prova e a cápsula de PVC foram devidamente etiquetados (Figura 5 e 6 ) com as seguintes informações: alerta sobre a composição e o perigo do material, número de registro do resíduo em planilha disponibilizada no site do PROGERE-UFC. A etiqueta do corpo de prova tem $10 \mathrm{~cm}$ de diâmetro e foi revestida com resina, para que não se danificasse rapidamente, e em sua base foram colocados pregos para que ficasse bem segura no corpo de prova. A etiqueta da cápsula de PVC foi envolta em fita adesiva para que não fosse danificada pelo cimento. Consta, ainda, na etiqueta da cápsula de PVC informação a respeito da data na qual o resíduo foi imobilizado.

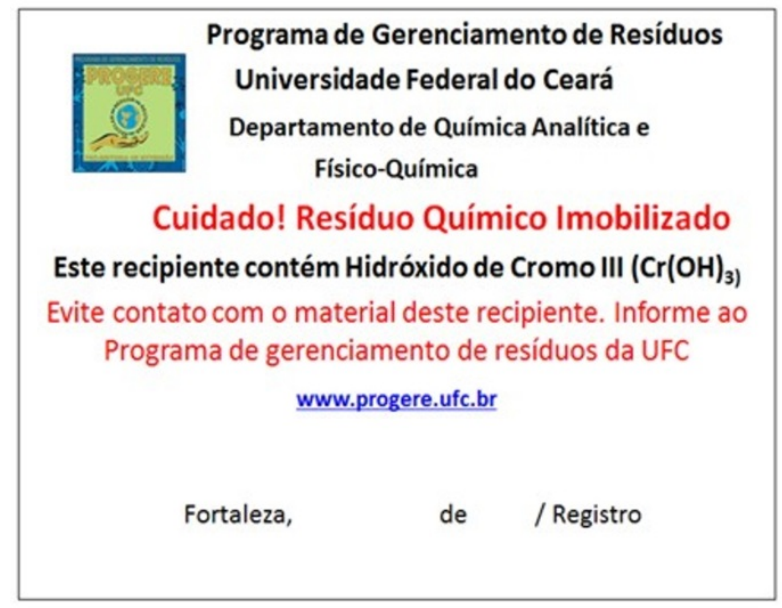

Figura 5. Etiquetas de imobilização da Cápsula de PVC

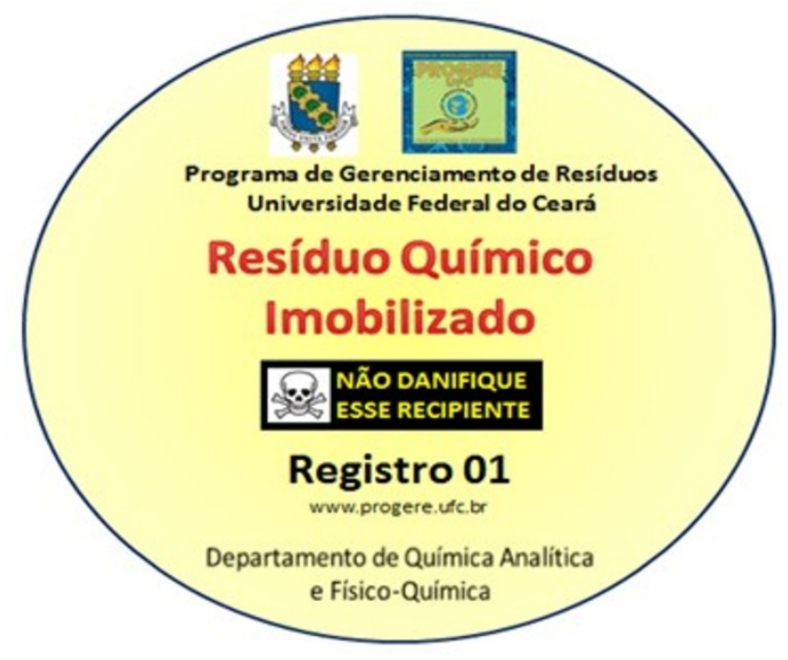

Figura 6. Etiquetas de imobilização do Corpo de Prova

Foi elaborada uma planilha, contendo o número de registro, data da imobilização e o conteúdo da cápsula, para documentar os resíduos imobilizados, que será disponibilizada no endereço www.progere.ufc.br.

\section{RESULTADOS E DISCUSSÃO}

\section{Comparação entre os métodos de tratamento efetuados}

O sobrenadante do resíduo filtrado (SRF) e os sobrenadantes recuperados dos tratamentos com bissulfito de sódio (STB) e tiossulfato de sódio (STT) foram submetidos aos testes qualitativos, recomendados pela literatura (Vogel, 1981) e análise por absorção atômica. Os precipitados oriundos dos tratamentos com bissulfito de sódio (PTB) e tiossulfato de sódio (PTT) foram submetidos à análise de fluorescência de raios-X.

\subsection{Testes qualitativos}

Como podemos verificar na Figura 7, não há presença do íon cromato, sensível ao teste qualitativo, nos sobrenadantes tratados, já os íons $\mathrm{SO}_{4}{ }^{2-}, \mathrm{SO}_{3}{ }^{2-}$ e $\mathrm{S}_{2} \mathrm{O}_{3}{ }^{2-}$ aparecem devido aos processos do tratamento. 


\begin{tabular}{|l|l|l|l|}
\hline & SRF & STB & STT \\
\hline $\mathrm{CrO}_{4}{ }^{2-}$ & $\checkmark$ & - & - \\
\hline $\mathrm{Ca}^{2+}$ & - & - & - \\
\hline $\mathrm{CO}_{3}{ }^{2-}$ & $\checkmark$ & $\checkmark$ & $\checkmark$ \\
\hline $\mathrm{Ag}^{+}$ & - & - & - \\
\hline $\mathrm{Cl}^{-}$ & - & - & - \\
\hline $\mathrm{SO}_{4}{ }^{2-}$ & - & $\checkmark$ & $\checkmark$ \\
\hline $\mathrm{SO}_{3}{ }^{2-}$ & - & $\checkmark$ & $\checkmark$ \\
\hline $\mathrm{S}_{2} \mathrm{O}_{3}{ }^{2-}$ & - & - & $\checkmark$ \\
\hline
\end{tabular}

$(-)$ : ausente $(\checkmark)$ : presente

Figura 7. Resultado dos testes qualitativos dos sobrenadantes

\subsection{Análise por absorção atômica}

A determinação do teor de cromo total foi realizada no Laboratório de Análises e Traços do DQAFQ, utilizando-se a chama de ar/acetileno em espectrômetro de absorção atômica (EAA) Varian, modelo AA240FS. Tabela 1

Os resultados obtidos estão expostos na

Tabela 1. Resultado da análise por absorção atômica dos sobrenadantes.

\begin{tabular}{l|l}
\hline Amostra & $\mathbf{C r}\left(\mathbf{m g} \cdot \mathbf{L}^{-1}\right)$ \\
\hline SRF & 263 \\
\hline STB & 0,545 \\
\hline STT & 1,198 \\
\hline
\end{tabular}

Podemos perceber que os tratamentos aplicados foram eficientes, pois a concentração de cromo total diminuiu de maneira considerável. Observou-se para o tratamento com bissulfito de sódio uma redução de $99,79 \%$ na concentração de cromo total e com tiossulfato de sódio $99,54 \%$. Entretanto, apenas o tratamento com bissulfito de sódio apresentou concentração de cromo total próximo do limite de $0,5 \mathrm{mg}^{-\mathrm{L}^{-1}}$ estabelecido pela resolução N³57/2005 CONAMA.

\subsection{Análise por fluorescência de raios-x}

A análise dos precipitados $\left(\mathrm{Cr}(\mathrm{OH})_{3}\right)$ foram realizadas no Espectrômetro de Fluorescência de Raios-X da marca Rigaku e modelo ZSX Mini II, no Laboratório de Raio-X
(Departamento de Física da UFC).

Observando a Figura 8 verificamos que a precipitação foi eficiente, pois ambos os precipitados apresentaram mais de $85 \%$ em massa de cromo.

De acordo com os resultados apresentados na Figura 8, o método que utiliza bissulfito de sódio apresentou melhores resultados do que o método com tiossulfato de sódio. Destaca-se ainda que o segundo método (tiossulfato de sódio) apresenta uma etapa a mais no tratamento, que utiliza ácido sulfúrico. Assim, sugere-se que 0 tratamento com tiossulfato de sódio seja utilizado apenas como uma segunda opção.

Apesar do tratamento com tiossulfato de sódio apresentar aproximadamente o dobro da concentração de cromo total permitida pela legislação, não é recomendável repetir o tratamento para reduzir ainda mais a concentração de cromo, em virtude da impossibilidade de precipitar a pequena quantidade de cromo remanescente.

\section{Imobilização}

Cada cápsula de PVC pode conter aproximadamente $131 \mathrm{~g}$ de $\mathrm{Cr}(\mathrm{OH})_{3}$, contando também com a massa do papel de filtro.

Foi sugerida a utilização de um cilindro de metal devido a sua maior resistência, entretanto, esta ideia foi descartada, pois pode ocorrer a corrosão do metal fazendo com que haja a expansão do mesmo e danificação do corpo de prova, além de poder acontecer a contaminação do precipitado com os produtos de corrosão do metal.

No caso de quebra do corpo de prova é possível por meio da planilha localizada no site www.progere.ufc.br, que documenta os resíduos imobilizados, saber qual material esta dentro da cápsula de PVC permitindo, assim, dar um destino adequado para o mesmo, evitando acidentes pessoais e ambientais.

\section{Minimização do passivo ambiental}

PERIÓDICO TCHÊ QUÍMICA • www.periodico.tchequimica.com • Vol. 12 N. 24 - ISSN 1806-0374 (impresso) • ISSN 1806-9827 (CD-ROM) • ISSN 2179-0302 (meio eletrônico) 
Com os tratamentos do resíduo do método de Mohr com bissulfito de sódio e tiossulfato de sódio foi possível diminuir o volume do resíduo estocado (116L/2014.2) em aproximadamente $56,03 \%$, pois para cada 100 $\mathrm{mL}$ de sobrenadante tratado, foi originado aproximadamente $0,5 \mathrm{~g}$ de $\mathrm{Cr}(\mathrm{OH})_{3}$, sendo necessário tratar $65 \mathrm{~L}$ de resíduos para preencher 3 cápsulas de PVC, o que corresponde aproximadamente ao resíduo gerado em 8 semestres de aulas experimentais.

Além disso, a massa de concreto produzida nas aulas das disciplinas Materiais de construção I e II, que era descartada incorretamente, terá reaproveitamento na demarcação de jardins, deixando, assim, de se tornar um passivo ambiental. Além disso, a imobilização realizada possibilita o tratamento e/ou reutilização futura do resíduo.

\section{CONCLUSÃO}

Os tratamentos do resíduo contendo $\mathrm{Cr}(\mathrm{VI})$ utilizando bissulfito de sódio e tiossulfato de sódio, podem ser considerados efetivos, pois apresentaram redução na concentração de cromo total em $99,79 \%$ e $99,54 \%$, respectivamente. Foi possível o descarte do sobrenadante após os tratamentos, com devida neutralização, já que as concentrações de cromo total estavam próximas às estabelecidas pela resolução $\mathrm{N}^{\circ} 357 / 2005$ do CONAMA, ou seja, $0,545 \mathrm{mg} \cdot \mathrm{L}^{-1}$ para o tratamento com bissulfito de sódio e 1,198 mg. $\mathrm{L}^{-1} \mathrm{com}$ tiossulfato de sódio.

A imobilização de resíduos químicos sólidos em cápsulas de PVC/corpo de prova mostrou-se ser uma solução limpa, rápida e simples, podendo ser considerada uma forma de disposição final ambientalmente correta para muitos outros resíduos sólidos contendo metais pesados.
Os procedimentos efetivados diminuíram consideravelmente 0 volume de passivos ambientais no Laboratório de Química Analítica Quantitativa do DQAFQ da UFC.

\section{REFERÊNCIAS}

1. Amour, M. A. Hazardous laboratory chemicals disposal guide. 3th., Florida: Boca Raton, 2005.

2. Concelho Nacional de Meio Ambiente/357: Estabelece as condições e padrões de lançamento de efluentes. Brasília, 2005.

3. Cavalcante, D. A.; Silva, M. S. P., Borges, S. S. S. Resumos do $2^{\circ}$ Simpósio Nacional sobre Tratamento de Resíduos de Laboratório, Rio de Janeiro, Brasil, 2012. 5.

4. Gutterres, M. Silva, M. C.; Dettimer, A. Dossiê sobre Cromo. 2011.

5. http://www.labmastercientifica.com.br, acessado em Julho 2014.

6. http://www.icp.csic.es, acessado em Julho de 2014.

7. Oliveira, E. S. et al.. Resumos do $50^{\circ}$ Congresso Brasileiro de Química, Cuiabá, Brasil, 2010.

8. Paulino, C.V.H. Dissertação de Mestrado, Pontifícia Universidade Católica, Rio de Janeiro, 1993.

9. Rivetti, L. C. et al. Revista IberoAmericana de Ciências Ambientais, 2012, $3,98$.

10. VAZ, A. J.; LIMA, I. V.. Em Metais: Gerenciamento da toxicidade Imunotoxicologia dos metais; Azevedo, F. A.; Chasin, A. A. M. eds.; Editora Atheneu: São Paulo, 2003, cap 13.

11. Vogel, A. I.; Química Analítica Qualitativa. 5. ed. Mestre Jou: São Paulo, 1981 


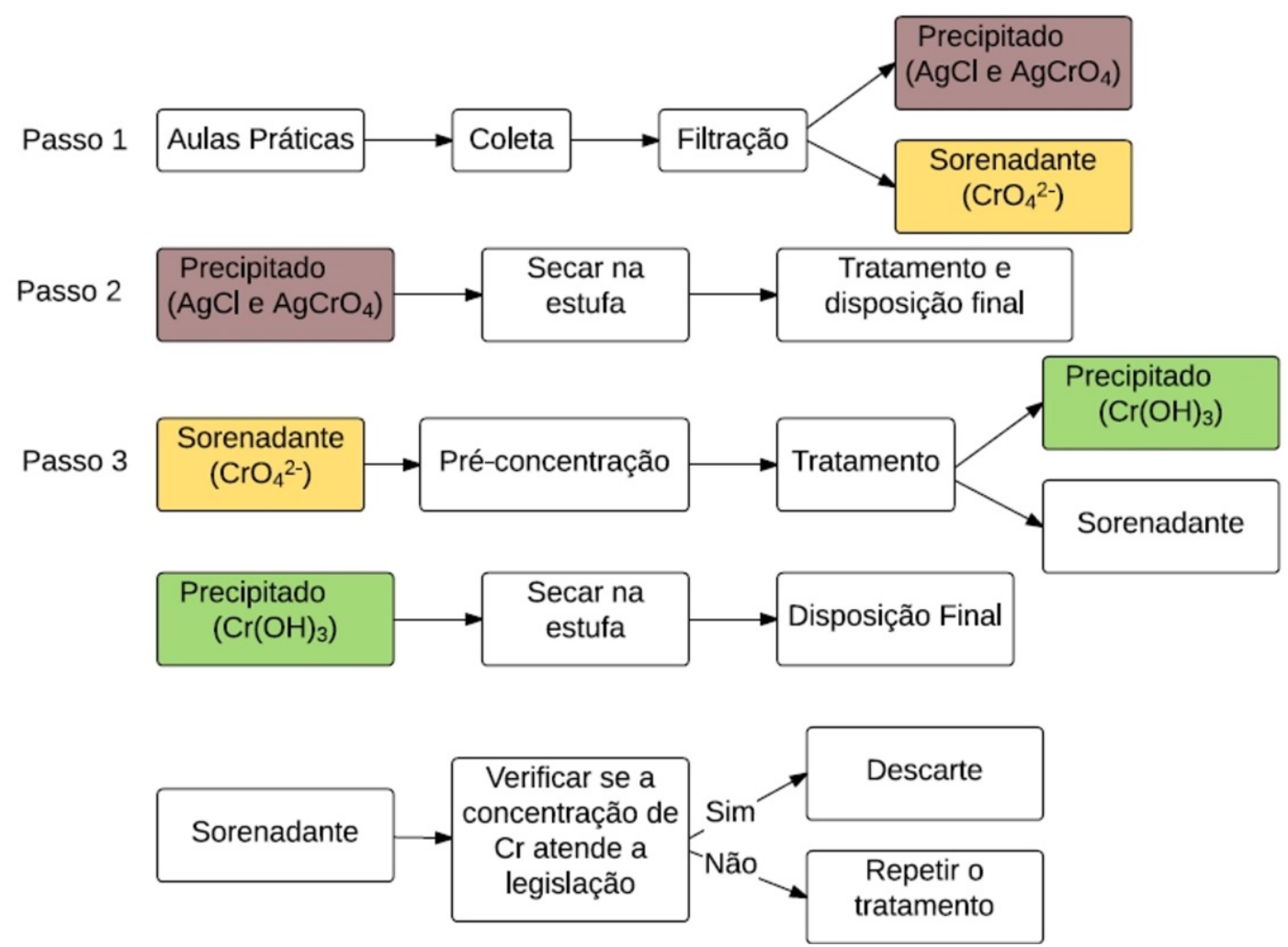

Figura 3. Fluxograma da gestão do resíduo do método de Mohr.

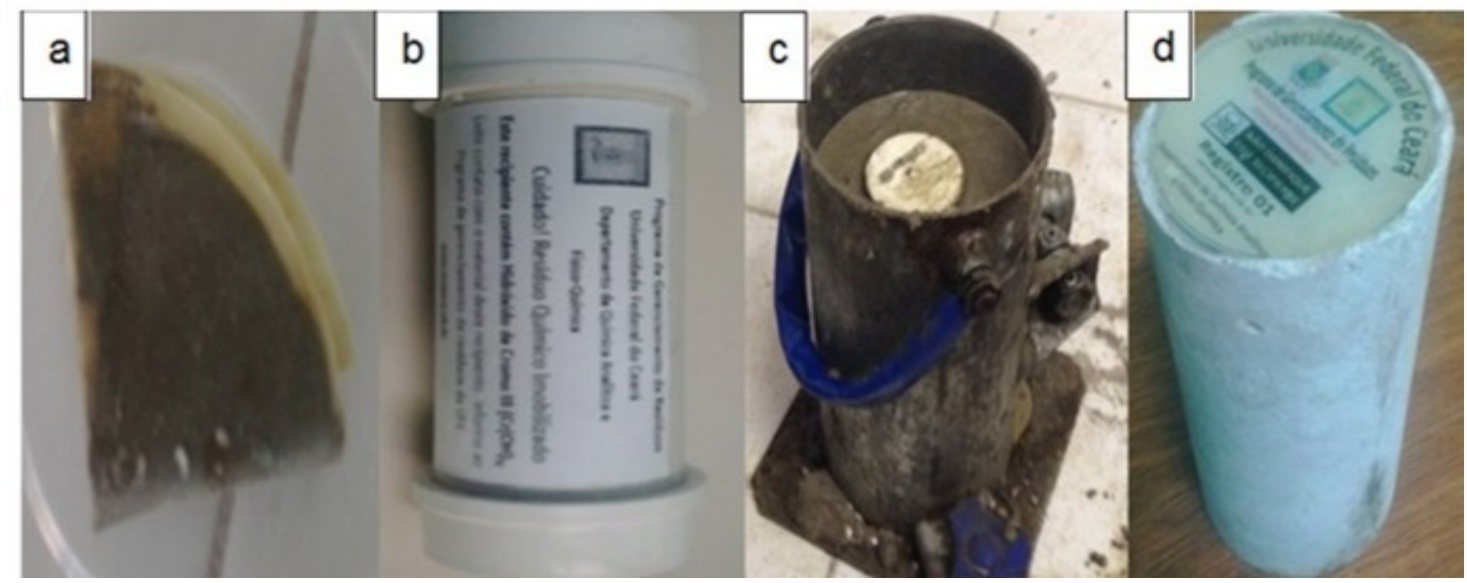

Figura 4. (a) precipitado pronto para ser imobilizado, (b) cápsula de PVC, (c) encerramento da cápsula de PVC no corpo de prova, (d) produto final. 


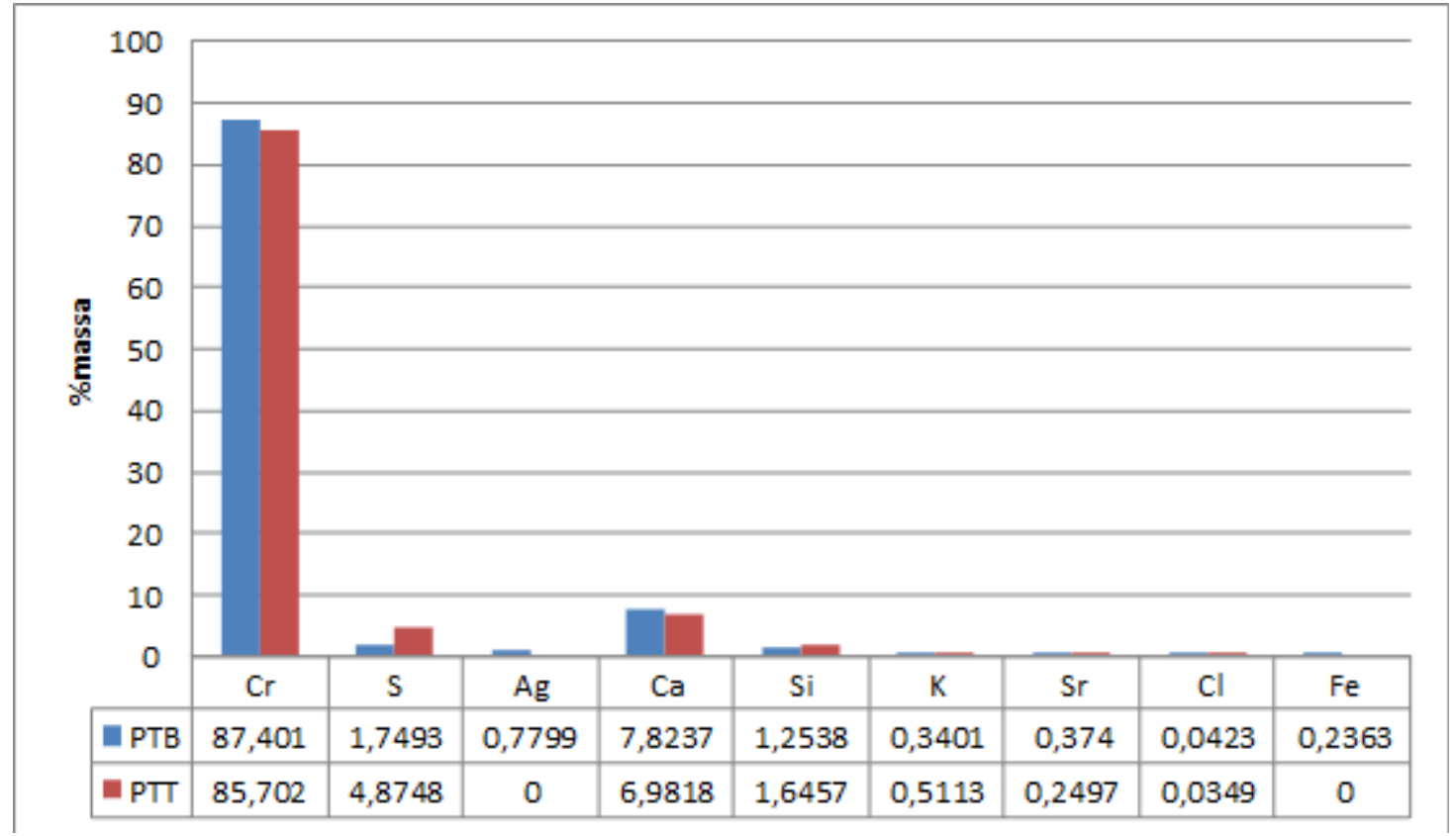

Figura 8. Distribuição da \%massa no precipitado oriundo do tratamento utilizando bissulfito de sódio (azul) e tiossulfato de sódio (vermelho).

PERIÓDICO TCHÊ QUÍMICA • www.periodico.tchequimica.com • Vol. 12 N. 24

• ISSN 1806-0374 (impresso) • ISSN 1806-9827 (CD-ROM) • ISSN 2179-0302 (meio eletrônico)

(C) 2015. Porto Alegre, RS. Brasil

The Periódico Tchê Química (ISSN: 1806-0374; 2179-0302) is an open-access journal since 2004. Journal DOI: 10.52571/PTQ. http://www.tchequimica.com. This text was introduced in this file in 2021 for compliance reasons.

() The Author(s)
OPEN ACCESS. This article is licensed under a Creative Commons Attribution 4.0 (CC BY 4.0) International License, which permits use, sharing, adaptation, distribution, and reproduction in any medium or format, as long as you give appropriate credit to the original author(s) and the source, provide a link to the Creative Commons license, and indicate if changes were made. The images or other third-party material in this article are included in the or exceeds the permitted use, you will need to obtain permission directly from the copyright holder. To view a copy of this license, visit http://creativecommons.org/licenses/by/4.0/. 